\title{
Role of bhramari pranayama in generalised anxiety disorder
}

\author{
Ketaki Hemant Patil*1, Vidya Wasnik (Thatere) ${ }^{2}$, Sumeeta S. Jain ${ }^{3}$ \\ ${ }^{1}$ PG Scholar, ${ }^{2}$ Associte Professor, ${ }^{3}$ HOD and Professor, \\ Department of Swasthvritta and Yoga \\ Government Ayurved College, Nagpur, Maharashtra, India \\ *Corresponding Author: ketakipati10707@gmail.com
}

\section{ABSTRACT:}

Pranayama is a Yogic technique which ensure homeostasis between physical and mental health. Bhramari is one of the 8 types of Pranayama as explained by Sage Patanjali which is considered to be effective in maintaining mental health. The following article discusses the probable use of Bhramari in Generalised Anxiety Disorder (GAD). Various publications from Pubmed, Google Scholar, Scopus etc were reviewed to reinforce the hypothesis that Bhramari can be effective in GAD. It is worthwhile known that Bhramari is effective in various stressful conditions but its efficacy against GAD is not yet proven. Since GAD is one of the most common mental disorders, it is hypothesised that Bhramari acts good against GAD too. Hence, it can be concluded that it would be beneficial to conduct larger studies on GAD patients to ascertain the efficacy of Bhramari in their population.

Keywords: Generalised Anxiety Disorder, Bhramari Pranayama, Anxiety, Yoga, HARS

\section{INTRODUCTION}

Yoga is an ancient life science which has its origin in India. Since then, various forms of Yoga are practiced all over the world like Vinyasa Yoga, Hatha Yoga, Iyengar Yoga, Kundalini Yoga, Ashtanga Yoga, Bikram Yoga, Yin Yoga etc. Yoga is proved to be effective not only in maintaining the physical health but also mental health. It is being practiced in the form of Asana, Pranayama, Bandha, Mudras and Meditation. Out of these, Pranayama is the 4th pillar of Ashtanga Yog described by sage Patanjali primarily focusing on regulation of breath. Pranayama is a Sanskrit word descended from 2 main words 'Prana' meaning 'life force, the cosmic vital energy' and 'Ayama' meaning 'stretch or expand' which means to expand the dimensions of Prana within the self. Deep inhalation of fresh air heals, rejuvenates and revitalises the system while deep exhalation removes toxins from body as well as mind. Maharishi Patanjali, in his Ashtanga Yoga, has given more importance to Pranayama than Asana for good health ${ }^{[1]}$. Practicing Pranayama regularly has a positive impact on cardiovascular, and respiratory functions, improves the autonomic system towards parasympathetic (vagal tone) dominance which in turn reduces the effects of stress and strain on various 
systems improving the overall physical and mental health ${ }^{[2]}$.

Generalised anxiety disorder is one such condition characterised by excessive worry which may affect their life in many aspects. Every person may have experienced at least a single episode of GAD during his/her lifetime. The risk of developing GAD at any point in life has been estimated at $9.0 \%{ }^{[3]}$. Excessive anxiety is nonadaptive which is often considered to be a component of an unhealthy lifestyle which can not only affect the psychiatric health but also the systemic health. There are various studies indicating the efficacy of Pranayama in treating mental disorders. Bhramari is one of the most widely practiced Pranayamas which has various mental health benefits. Bhramari influences multiple systems in the body and desirable effects on respiratory system, autonomic nervous system, stress, anxiety level, over all emotional status of the practitioner etc. ${ }^{[2]}$. The following article illustrates the role of Bhramari Pranayama in Generalised Anxiety Disorder.

\section{Generalised anxiety disorder (GAD):} Generalized anxiety disorder (GAD) a mental and behavioral disorder, specifica lly an anxiety disorder characterized by excessive, uncontrollable and often irrational worry about events or activities $^{[4]}$. Symptoms may include excessive worry, restlessness, trouble sleeping, exhaustion, irritability, sweating, and trembling which may interfere with their life in terms of health, family, finances and work $^{[5]}$. GAD at time 1 increases the likelihood of first onsets of mood disorders, panic disorder, posttraumatic stress disorder, and substance abuse disorders at time $2^{[6]}$. Most people with GAD also have other psychiatric disorder, history of trauma or a family with GAD. Lifetime prevalence of GAD is estimated at about $5.7 \%$, and 12month prevalence is $3.1 \%^{[7]}$.
Exact pathophysiology of GAD is not known yet. The serotonin system and the noradrenergic systems are common pathways involved in anxiety. Many believe that low serotonin system activity and elevated noradrenergic system activity are responsible for its development ${ }^{[8]}$. Several regions of brain like the amygdala, insula and the frontal cortex that mediate the processing of stimuli associated with fear, anxiety, memory, and emotion are involved in the pathophysiology of $\mathrm{GAD}^{[9]}$. It has been suggested that individuals with GAD have greater amygdala and medial prefrontal cortex (mPFC) activity in response to stimuli than individuals who do not have $\mathrm{GAD}^{[9]}$. The diagnostic criteria for GAD is the Diagnostic and Statistical Manual of Mental Disorders DSM-5 (2013), published by the American Psychiatric Association $^{[4]}$. But the most commonly used clinician rating scale to measure the effect of treatment is the Hamilton anxiety scale, a 14 item instrument with a global score of $42^{[10]}$.

Treatment response is generally defined as a 50\% reduction in baseline score. Clinical recovery is often defined as a score of less than 7 on the Hamilton anxiety scale ${ }^{[10]}$. Treatment includes psychotherapy (e.g., cognitive behavioral therapy or metacognitive therapy) and pharmacological intervention (e.g., citalopram, escitalopram, sertraline, duloxetine, and venlafaxine) out of which CBT and selective serotonin reuptake inhibitors (SSRIs) are first line psychological and pharmacological treatments; other options include selective norepinephrine reuptake inhibitors $(\text { SNRIs })^{[9]}$.

\section{PRANAYAMA:}

Pranayama involves the practice of breath control in combination with Bandhas and Mudras. Pranayama comprises of 8 types i.e. Ashta-Kumbhakas namely Suryabhedi, Ujjayi, Seetkari, Sheetali, Bhastrika, Bhramari, Murcha and 
Plavini ${ }^{[11]}$. Pranayama basically consists of 3 phases namely - 1. Puraka (inhalation), 2. Kumbhaka (breath retention) and Rechaka (exhalation) where Kumbhaka is the most important aspect of Pranayama $^{[12]}$. According to Yogic texts, the proportion of time to be allotted to the three steps is 1:4:2 respectively for inhaling, controlling and exhaling the breath $^{[13]}$. Kumbhaka when mastered arouses inherent potentials in the higher regions of the whole brain. There are 2 ways to perform Kumbhaka where external retention is called as Bahiranga Kumbhaka and internal retention is Antaranga Kumbhaka ${ }^{[14]}$. Retention of breath and extended voluntary expiration leads to raise in intra-thoracic pressure causing more blood flow to the heart from lung and thus increasing the stroke volume which in turn increases the blood pressure stimulating the baroreceptors in carotid sinus. Further, this increased baroreceptor discharge inhibits the vasoconstrictor nerves and excites the vagus innervations of the heart which is then responsible for a drop in blood pressure and heart rate ${ }^{[15]}$ leading to the activation of parasympathetic nervous system. It has been hypothesized that the psychobiological mechanism through which Pranayama exerts its effects are mediated by the vagus nerve, through interconnections between peripheral sensory organs, the solitary nucleus, thalamus, limbic areas, and the prefrontal corte $^{[16]}$. In other studies on the Yogic breathing, it has been reported that Pranayamas are effective in improving cognitive performance, bringing relaxation, improving spatial memory performances $^{[17]}$.

\section{BHRAMARI PRANAYAMA:}

Bhramari is one of the most important Pranayamas which is commonly practiced all over the world irrespective of age and gender is a slow and deep breathing technique ${ }^{[2]}$. Bhramari is a Sanskrit word meaning 'Bumble bee', so called because the sound made during respiration imitates that of a black bee. The technique involves breathing in quickly, making a reverberating sound like the male black bee, and exhaling slowly while softly making the sound of the female black bee keeping the mouth closed by lips and ears closed by fingers. By this Yogic practice one becomes lord of the Yogis and the mind is absorbed in bliss ${ }^{[18]}$.

The eyes must be closed during this process to cut down external inputs of sound and sight to internalize the consciousness. The humming volume should be effortless, mellow, loud and steady enough to create vibrations in the brain. Bhramari should be practiced in an empty stomach after practicing Asana, Nadishodhana and dynamic forms of Pranayama and before meditation or sleep. It is better to practice Bhramari in the early hours of the morning or late at night as it helps to awaken psychic sensitivity and arouse awareness of subtle vibrations of energy. The sound produced in Bhramari is very soothing and thus the practice relieves mental tension and anxiety and helps reduce anger.

Technique 1:

Sit in any comfortable meditative pose, relax the body and keep the eyes closed throughout the practice. Inhale slowly and deeply through the nose, listening to the sound of the breath. Close the ears with the index finger by pressing the tragus into the ear hole. Keep the ears closed and exhale, making a deep soft humming sound. Concentrate on the sound, keeping it low pitched. When exhalation is complete, lower the hands to the knees and breathe in slowly. Continue to practice in the same way, performing ten to twenty rounds. When finished, keep the eyes closed and listen for any subtle sounds.

Technique 2

Stage 1: Practice in the same way as Technique 1, but after exhalation perform 
Bahirkumbhaka and Jalandhar Bandha. Practice ten to twenty rounds, taking a few normal breaths between rounds if necessary.

Stage 2: Practice as in stage 1, but add Moola Bandha after Jalandhar.

Technique 3

Stage 1: Practice Technique 1 with Shanmukhi Mudra. That is, after inhalation do Kumbhaka and close the ears with the thumbs, the eyes with the first fingers, the nostrils with the middle fingers, the mouth with the ring and the chin with little finger. Hold for as long as comfortable, then exhale maintaining the same hand position. Keep your awareness on the subtle sound vibrations or any images that may appear in front of the closed eyes.

Stage 2: Practice stage 1 with Shanmukhi Mudra, but add Moola Bandha.

\section{DISCUSSION:}

\section{Physiological changes during and after Bhramari:}

A recent feasibility study found evidence of the positive impact of Pranayama in patients with treatmentresistant $\mathrm{GAD}^{[19]}$. Bhramari is one such Pranayama which is mainly recommended for reducing mental problems such as tension, cerebral tension, hypertension, anxiety and controlling blood pressure ${ }^{[20]}$. Immediately after $5 \mathrm{~min}$ of practice of Bhramari, the heart rate and blood pressure is influenced in healthy subjects because of the parasympathetic dominance $^{[21]}$. It has been suggested that the increase of parasympathetic activity (associated with expiration time) reduces the release of hormones associated with stress, and enhances GABA inhibition from the prefrontal cortex and insula to the amygdala, reducing its activity, and the psychological and somatic symptoms associated with stress ${ }^{[16]}$.

Short inhalation and self induced humming sound during the slow, deep and prolonged exhalation in Bhramari imitates the Mantra chanting technique of meditation. According to a study, Bhramari Pranayama was well accepted by the students because of its simplicity, the humming sound produced during the practice and the mimicking group chanting induced deep state of relaxation like meditation ${ }^{[15]}$. Practice of Bhramari for $5-10 \quad \min$ continuously induce subjective feelings of mind refreshment and blissfulness and sometimes the subjects are believed to go to even meditative state ${ }^{[22]}$. Since, for brain we don't have any stretching exercises like other parts of the body, vibration of head is a good alternative for that and vibration by one's own voice might not be harmful for the brain tissues ${ }^{[2]}$. The self-produced sound and vibrations enhance the level of consciousness. According to a study, Bhramari significantly reduced the irritability, depression and anxiety associated with tinnitus ${ }^{[23]}$. A research conducted on Bhramari Pranayama showed the dominance of alpha, paroxysmal gamma and theta waves in EEG immediately after practicing Bhramari, where alpha waves are responsible for imparting deep relaxation, gamma waves are related with the performance of higher mental activities and perceptual tasks while theta waves are responsible for increasing creativity, learning, reducing stress, awakening intuition and development of other extraordinary perception skills ${ }^{[20]}$.

\section{CONCLUSION:}

Thus, it can be concluded that Bhramari can be effective in reducing the symptoms associated with GAD. More research should be conducted in the form of clinical trials using larger population and for a longer duration to prove its efficacy in GAD and other mental disorders.

\section{REFERENCES:}

1. Veerabhadrappa S.G., Herur A., Patil S. Effect of yogic bellows on cardiovascular autonomic 
reactivity. J Cardiovasc Dis Res. 2011;2(4):223-227.

2. Kuppusamy M, Kamaldeen D, Pitani R, Amaldas J,

Shanmugam P. Effects of Bhramari Pranayama on health-A systematic review. J Tradit Complement Med 2018;8:11-6

3. Kessler, Ronald C.; Petukhova, Maria; Sampson, Nancy A.; Zaslavsky, Alan M.; Wittchen, Hans-Ullrich (September 2012). "Twelve-month and lifetime prevalence and lifetime morbid risk of anxiety and mood disorders in the United States". International Journal of Methods in Psychiatric Research. 21 (3): 169-184. Doi:10.1002/mpr.1359. ISSN 1557-0657. PMC 4005415. PMID 22865617.

4. Diagnostic and statistical manual of mental disorders : DSM-5 ( $5^{\text {th }}$ ed.). Washington, D.C.: American Psychiatric Association. 2013. P. 222. ISBN 978-0-89042-554-1.

5. "Generalized Anxiety Disorder: When Worry Gets Out of Control". NIMH. Retrieved 30 May 2019.

6. Ruscio AM, Chiu WT, Roy-Byrne P, Stang PE, Stein DJ, et al. Broadening the definition of generalized anxiety disorder: effects on prevalence and associations with other disorders in the National Comorbidity Survey Replication. J Anxiety Disord. 2007;21:662-76.

7. Kessler RC, Wang PS. The descriptive epidemiology of commonly occurring mental disorders in the United States. Annu Rev Public Health. 2008;29:115-29.

8. Munir S, Takov V. Generalized Anxiety Disorder. [Updated 2021 May 8]. In: StatPearls [Internet]. Treasure Island (FL): StatPearls Publishing; 2021 Jan-. PMID: 28722900.
9. Anxiety Disorders (chapter 32)". Massachusetts General Hospital comprehensive clinical psychiatry. Stern, Theodore A., Massachusetts General Hospital (Second ed.). London. 13 February 2015. ISBN 978-0-323-32899-9. OCLC 905232521.

10. Gale C, Davidson O. Generalised anxiety disorder. BMJ. 2007 Mar 17; 334(7593): 579-581.

11. Muktibodhananda S. Hatha Yoga Pradipika. $3^{\text {rd }}$ ed. Shatkarma and Pranayama, Chapter 2, Verse 21. Munger, Bihar: Yoga Publications Trust; 1998. p. 185.

12. Prof .(Dr) Mishra SP, Yoga and Ayurveda, Art\& ethics of yoga, choukhamba publication,2015,Chapter no 4,page no 49

13. Bhoyar S, Khan A, Tirpude S, Cahuragade N, Bhoyar K, Varma A. Effect Of Pranayama In Relieving Stress: A Review Article. European Journal of Molecular \& Clinical Medicine. 2021;08(01):161-5. ISSN 25158260

14. Samgandi K, Swasthvrittasudha, Ashtang Yog, Jagdish Sanskrit Pustakalaya, 2015, Chapter no 21, page no 214.

15. Kuppusamy M, Kamaldeen D, Pitani R, Amaldas J. Immediate Effects of Bhramari Pranayama on Resting Cardiovascular Parameters in Healthy Adolescents. Journal of Clinical and Diagnostic Research. 2016 May, Vol-10(5): CC17-CC19

16. Novaes MM, Palhano-Fontes F, Onias H, Andrade KC, LobãoSoares B, Arruda-Sanchez T, Kozasa EH, Santaella DF and de Araujo DB (2020) Effects of Yoga Respiratory Practice (Bhastrika pranayama) on Anxiety, Affect, and Brain Functional Connectivity and Activity: A Randomized 
Controlled Trial. Front.

Psychiatry 11:467. doi:

10.3389/fpsyt.2020.00467

17. Telles S, Nagarathna R, Nagendra HR. Breathing through a particular nostril can alter metabolism and autonomic activities. Indian J Physiol Pharmacol (India) 1994 Apr; 38(2): 133-7.

18. Muktibodhananda S. Hatha Yoga Pradipika. $3^{\text {rd }}$ ed. Shatkarma and Pranayama, Chapter 2, Verse 68. Munger, Bihar: Yoga Publications Trust; 1998. p. 260.

19. Tiwari N, Sutton M, Garner M, Baldwin DS. Yogic Breathing Instruction in Patients with Treatment-Resistant Generalized Anxiety Disorder: Pilot Study. Int J Yoga (2019) 12:78-83. doi: 10.4103/ijoy.IJOY_22_18
20. Prasad R, Matsuno F, Bakardjian H, Vialatte F, Cichocki A. EEG changes after Bhramari Pranayama. SCIS\&ISIS2006 @ Tokyo, Japan (September 20-24, 2006)

21. Pramanik T, Sharma HO, Mishra S, Mishra A, Prajapati R, Singh S. Immediate effect of slow pace bhastrika pranayama on blood pressure and heart rate. The Journal of Alternative and Complementary Medicine. 2009;15(3):293-95

22. Rajkishor P, Fumitoshi M, Bakardjia H, Vialatte F, Cichocki A. EEG changes after Bhramari Pranayama. In: Paper Presented at: SCIS \& ISIS.2006

23. Pandey S., Mahato N.K., Navale R. Role of self-induced sound therapy: bhramari pranayama in tinnitus. Audiol Med. 2010;8(3):137-141.

Conflict of Interest:

DOI:

Non

https://doi.org/10.52482/ayurline.v5i03.575

Source of funding: Nil

Cite this article:

Role of bhramari pranayama in generalised anxiety disorder

Ketaki Hemant Patil, Vidya Wasnik (Thatere), Sumeeta S. Jain

Ayurline: International Journal of Research In Indian Medicine 2021; 5(4):01-06 